\title{
ZASTOSOWANIE KSZTAKTEK Z PVC JAKO FORM NEGATYWOWYCH DO WYKONYWANIA ODLEWÓW BETONOWYCH W PRAKTYCE RZEŹBIARSKIEJ
}

\author{
Michał Banaszek $^{1 凶}$, Kinga Rybak-Niedziółka ${ }^{2}$ \\ ${ }^{1}$ Instytut Inżynierii Środowiska \\ ${ }^{2}$ Instytut Inżynierii Lądowej \\ Szkoła Główna Gospodarstwa Wiejskiego w Warszawie
}

\begin{abstract}
STRESZCZENIE
W artykule zaprezentowano metodę odlewania kameralnych form betonowych przy wykorzystaniu produktów wykonanych z PVC, szeroko dostępnych w handlu materiałami budowlanymi. Przeprowadzone próby praktyczne miały na celu określenie stopnia złożoności wykonania takiego odlewu w odniesieniu do tradycyjnych metod polegających na skuwaniu gipsowych form negatywowych. Próbom poddano również podatność wybranych produktów budowlanych PVC na modyfikację kształtu przed wykonaniem odlewu przez miejscowe rozgrzewanie ścianek produktu temperaturą o maksymalnej wartości $550^{\circ} \mathrm{C}$.
\end{abstract}

Słowa kluczowe: rzeźba, odlewanie, beton, gips, glina, odkuwanie

\section{WSTĘP}

W artykule zastosowano zamienne terminy: forma negatywowa i powtoka negatywowa. Termin forma bez określnika negatywowa odnosi się do walorów związanych z kształtem i powierzchnią odlewu lub rzeźby.

Forma negatywowa w rzeźbie jest zbliżona funkcją do szalunku wykorzystywanego w budownictwie. Jej zadaniem jest utrwalenie wymodelowanego wcześniej kształtu. Sam odlew uzyskuje się przez wypełnienie formy negatywowej płynną materią, która po upływie czasu wiąże i twardnieje.

Modelowanie to proces polegający na formowaniu i dodawaniu miękkiego materiału, przeciwny rzeźbieniu polegającemu na kształtowaniu bryły poprzez jego ujmowanie (Karwowski, 1998). Produktem ujmowania będzie zatem rzeźba wykonana $\mathrm{w}$ kamieniu, drewnie lub dowolnej bryle materiału. Modelowanie w miękkim tworzywie jest pewnym etapem pracy rzeźbiarza, który zostaje utrwalony poprzez odlanie. Końcowym produktem modelowania będą rzeźby $z$ brązu lub innych stopów metali, żywic syntetycznych, betonu lub gipsu. Potoczne stwierdzenie, że spiżowy pomnik jest ,czyjegoś dłuta", w tej sytuacji będzie błędne, ponieważ rzeźba taka nie powstała w wyniku wykuwania (ujmowania) bryły, lecz właśnie poprzez modelowanie i późniejsze odlanie.

\section{CEL BADAŃ}

Celem badań było opracowanie metody odlewania $\mathrm{z}$ pominięciem procesu wykonywania form negatywowych z gipsu oraz równoczesne zminimalizowanie formalnych ograniczeń charakteryzujących formy negatywowe wykonane z szalunków.

Jedyną metodą na usunięcie gipsowych form negatywowych jest skuwanie ich z odlanego obiektu za 
pomocą narzędzi. Jak wykazuje praktyka, sposób ten generuje możliwość pęknięcia odlewanej formy betonowej. Beton ma małą wytrzymałość na rozciąganie (Pietrzak i Ulewicz, 2019). Drugą przyczyną jest często spotykana trudność w prawidłowym ocenieniu grubości powłoki gipsowej formy negatywowej, która z natury jest niejednorodna. Dochodzi wówczas do przebicia dłutem całej grubości formy negatywowej i wbicia narzędzia w odlew. Praktyka wykonywania gipsowych form negatywowych $\mathrm{z}$ wielu części determinuje również konieczność późniejszego retuszowania odlanego obiektu w miejscach ich połaczeń (tzw. nadlania). W bezpośrednim wyniku zakładano uzyskać metodę na odlanie betonowej formy o kształcie geometrycznym, przechodzącym w formę płynną o charakterze organicznym.

\section{MATERIA I METODY}

Najbardziej podstawowym sposobem utrwalenia modelu wykonanego w miękkim, plastycznym materiale jest odlew w gipsie za pomoca jednorazowych form gipsowych (Šahmenko, Aispursbi i Krasnikovs, 2015). Właściwości gipsu były już znane w starożytności (Werner, 1978). Płynny zaczyn gipsowy wiernie oddaje i utrwala najdrobniejsze detale (Guzera, 2010). Należy zwrócić uwagę, że w przypadku odlewu gipsowego formy negatywowe oraz odlew wykonane są $\mathrm{z}$ tego samego materiału. Zaletami tego rozwiązania są niskie koszty, łatwa dostępność składników oraz stosunkowo nieskomplikowany proces retuszu odlanego obiektu. Klasyczny odlew gipsowy jest traktowany zazwyczaj jako przejściowy etap utrwalenia modelu, a dzięki stosunkowo szybkiemu procesowi realizacji jest szeroko stosowany w szkolnictwie artystycznym. $\mathrm{W}$ uproszczeniu proces odlewania modelu wykonanego z miękkiej gliny rzeźbiarskiej za pomocą gipsowych form negatywowych przebiega następująco:

a) Narzucenie zaczynu gipsowego bezpośrednio na model (rys. 1). Jeśli wykonuje się formy negatywowe składające się z dwóch lub więcej części, podział form negatywowych odbywa się bezpośrednio na modelu za pomocą szeregowo wpuszczonych w glinę stalowych blaszek o optymalnej grubości $0,3-0,5 \mathrm{~mm}$. Podział form negatywowych powinien zostać przeprowadzony tak, aby poszcze- gólne jej części dały się zdjąć z modelu i ponownie złożyć w całość.

b) Po związaniu zaczynu następuje ręczne ściągnięcie form negatywowych z modelu oraz dokładne oczyszczenie $\mathrm{z}$ resztek materiału modelunkowego (rys. 2).

c) Kontrola pasowania oraz dokładna izolacja form negatywowych, zapobiegająca związaniu z materiałem, z którego wykonany będzie odlew.

d) Połączenie wszystkich części formy negatywowej i uszczelnienie połączeń (jeśli forma negatywowa będzie zalewana „na pełno”).

e) Wypełnienie formy negatywowej materiałem odlewniczym - istnieją dwie metody, które są zależne od wielkości i stopnia komplikacji kształtu modelu: przy mniejszych i prostszych formach jest to tzw. zalanie na pełno (por. pkt d), przy formach większych, bardziej skomplikowanych i z utrudnionym dostępem praktykuje się oddzielne wyłożenie każdej formy negatywowej kilkoma warstwami materiału odlewniczego $\mathrm{z}$ dodaniem siatek lub włókien zbrojących oraz stopniowe składanie i trwałe łączenie elementów w całość.

f) Po całkowitym związaniu odlewu następuje usunięcie zewnętrznej, gipsowej formy negatywowej poprzez odkucie jej narzędziami ręcznymi. Najczęściej stosuje się w tym celu młotek i płaskie dłuto ciesielskie (rys. 3).

$\mathrm{W}$ dalszym etapie utrwaloną $\mathrm{w}$ ten podstawowy sposób rzeźbę można wykorzystać jako model pomiarowy do przekucia np. w kamieniu, lub odlać w szlachetniejszym materiale, np. brązie.

Odmiennie wygląda postępowanie w przypadku odlewania gładkiej formy geometrycznej. Miękki, rzeźbiarski materiał, jakim jest glina lub plastelina, dobrze nadaje się do modelowania form organicznych, bogatych w faktury, płynne linie i detale, natomiast niezwykle trudno uzyskać jest za pomocą takiego modelunku poprawnie zbudowaną bryłę foremną o idealnie gładkich powierzchniach. W praktyce rzeźbiarskiej tego typu obiekty odlewa się, stosując m.in. szkło (odlewanie płytek gipsowych), płyty z tworzyw sztucznych (np. popularne „plexi” - PMMA) lub wykorzystywane $\mathrm{w}$ meblarstwie płyty laminowane. Wykonanie takiego odlewu nie wymaga uprzedniego modelowania, lecz precyzyjnego docięcia, złożenia i przygotowania form negatywowych (w swej istocie 
Rys. 1. Narzucanie zaczynu gipsowego na gliniany model rzeźby. Czerwonym kolorem zaznaczono wpuszczone w model blaszki podziału. Formę negatywową podzielono na dwie części

Fig. 1. Imposing a gypsum paste on a clay sculpture model. The division plate inserted into the model is marked in red. The negative form was divided into two parts
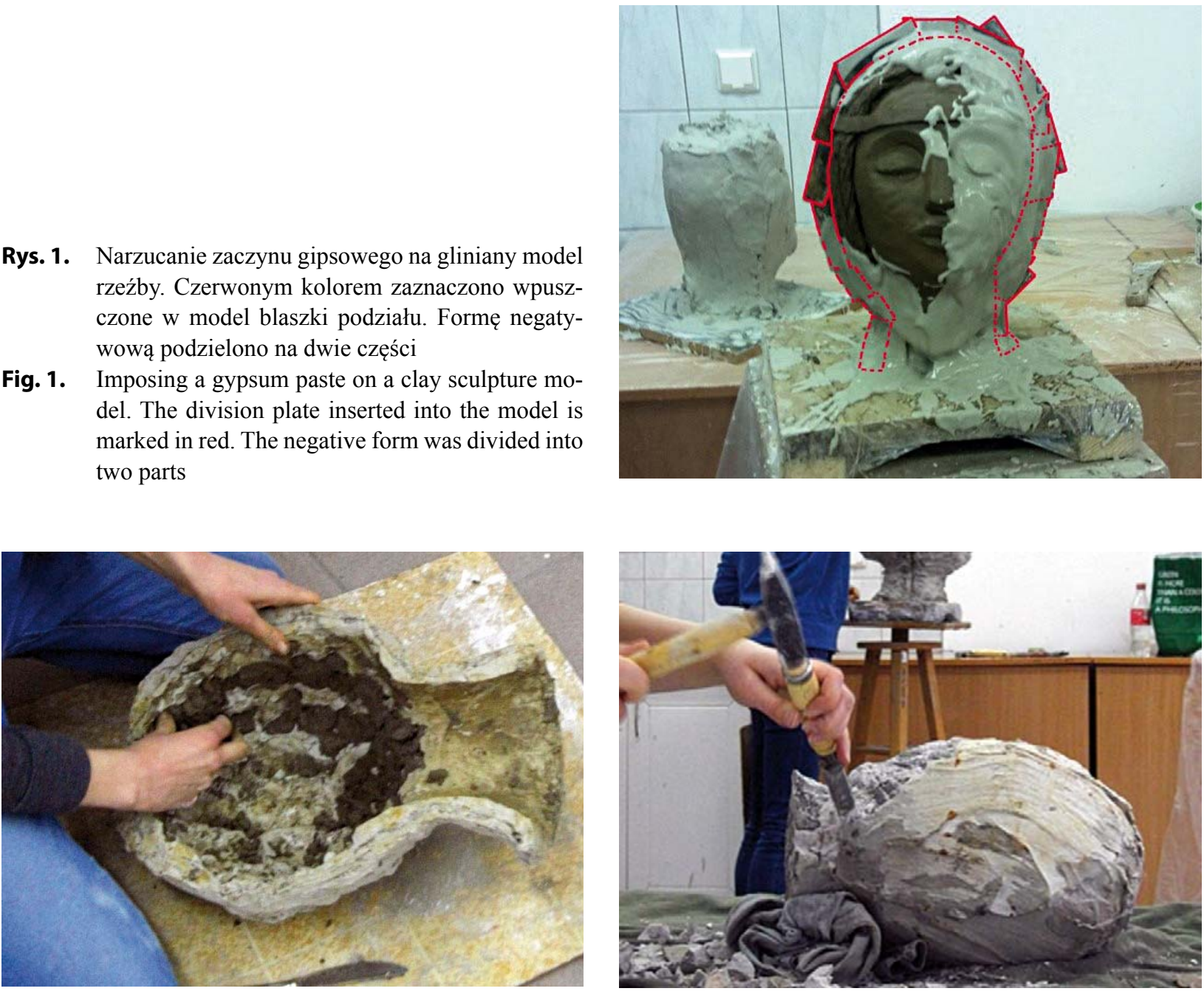

Rys. 2. Czyszczenie formy negatywowej

Fig. 2. Cleaning of negative form

Rys. 3. Skuwanie narzędziami formy negatywowej

Fig. 3. Forging a negative form by using tools

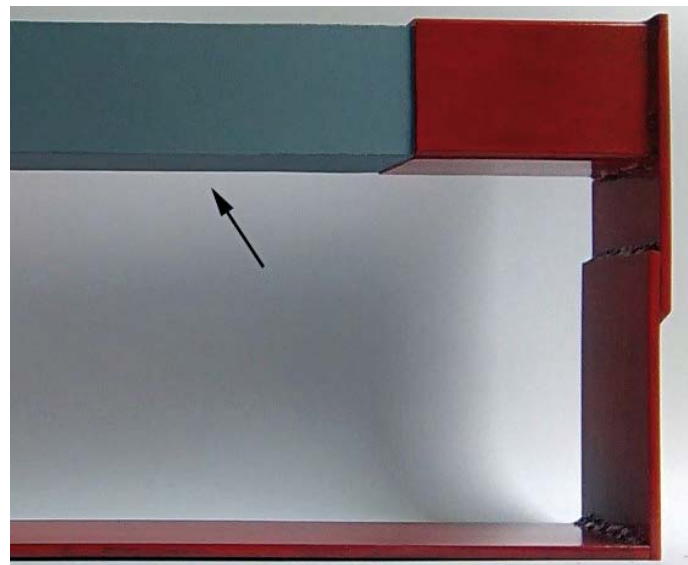


Banaszek, M., Rybak-Niedziółka, K. (2019). Zastosowanie kształtek z PVC jako form negatywowych do wykonywania odlewów betonowych w praktyce rzeźbiarskiej. Acta Sci. Pol. Architectura, 18 (4), 35-41. doi: 10.22630/ASPA.2019.18.4.43

płyt szalunkowych). Taki rodzaj odlewania (np. obiektów betonowych) jest najbardziej zbliżony do idei szalunku i deskowania w budownictwie (Trillo de Leyva i Dorado, 2017).

\section{PRZEPROWADZONE BADANIA I ZASTOSOWANE MATERIAtY}

Badania rozpoczęto od rozpatrzenia możliwości wykorzystania elementów budowlanych z poli(chlorku winylu) - PVC. Podstawą doboru produktów była ich wewnętrzna przestrzeń, która przewidywano wypełnić materiałem odlewniczym. Do prób zastosowano mieszankę Baumit B 30.

Poli(chlorek winylu) jest wykorzystywany do produkcji m.in. elementów stosowanych w budownictwie (Piszczek, 2009). Rozróżnia się dwa rodzaje tego tworzywa. Z twardej odmiany produkuje się m.in. elementy instalacji wodnych i kanalizacyjnych, a z miękkiej odmiany folie, ceraty, węże, izolacje (Kaczorowski, 2014).

Do próbnych odlewów wykorzystano rynnowe rury spustowe o średnicy zewnetrznej $75 \mathrm{~mm}$ i kanały wentylacyjne o przekroju prostokątnym o wymiarach zewnetrznych $55 \times 110 \mathrm{~mm}$. Grubość ścianek użytych elementów wynosiła $1,8 \mathrm{~mm}$. Istotną właściwością PVC, braną pod uwagę podczas wyboru materiału na formy negatywowe, jest termoplastyczność pozwalająca na modyfikowanie kształtu elementów przed wykonaniem odlewu. Cecha ta również umożliwiła późniejsze ściągnięcie powłoki negatywowej poprzez miejscowe nagrzewanie za pomocą opalarki elektrycznej i stopniowe rozrywanie powłoki. Zastosowano przy tym zakres temperatur emitowanych przez urządzenie od 350 do $550^{\circ} \mathrm{C}$.

\section{WYNIKI}

Wykonano dwanaście odlewów betonowych. W wyniku dotychczas przeprowadzonych prób opracowano następującą metodę postępowania:

a) Modyfikacja kształtu produktu z PVC pod wpływem działania temperatury za pomoca opalarki elektrycznej (rys. 5). Dodatkowe czynności: możliwość formowania rozgrzanego fragmentu poprzez wyginanie lub skręcanie.

b) Ustawienie powstałej powłoki negatywowej wlewem zorientowanym do góry na płaskiej powierzchni i ustabilizowanie w taki sposób, aby wykluczyć możliwość przechylenia lub przewrócenia formy negatywowej w trakcie zalewania (por. rys. 8).

c) Zewnętrzne uszczelnienie styku formy negatywowej z powierzchnią, na której została ustawiona, w przypadku jeśli jest formą o charakterze przelotowym (nie zamknięta). W tym celu należy zastosować gęsty zaczyn gipsu budowlanego lub silikon uniwersalny. Zalewanie można rozpoczać po całkowitym związaniu i sprawdzeniu uszczelnienia.

d) Zalanie wewnętrznej przestrzeni formy negatywowej mieszanką betonową (rys. 6).

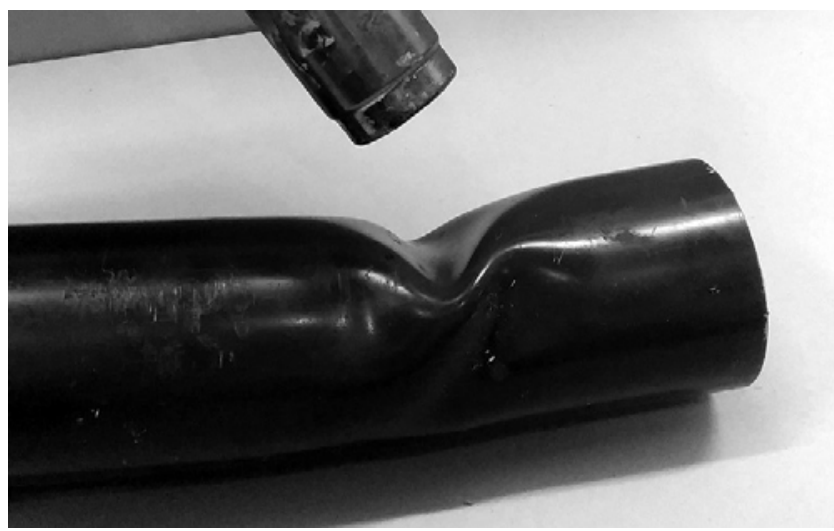

Rys. 5. Modyfikowanie kształtu formy negatywowej z PVC za pomocą opalarki elektrycznej

Fig. 5. Modifying the negative form of PVC shape using an electric heat gun 
Banaszek, M., Rybak-Niedziółka, K. (2019). Zastosowanie kształtek z PVC jako form negatywowych do wykonywania odlewów betonowych w praktyce rzeźbiarskiej. Acta Sci. Pol. Architectura, 18 (4), 35-41. doi: 10.22630/ASPA.2019.18.4.43

e) Po całkowitym związaniu odlewu następuje usunięcie powłoki negatywowej poprzez rozgrzewanie ścianek za pomocą opalarki elektrycznej i stopniowe rozrywanie powłoki (rys. 7). Dla ułatwienia tej

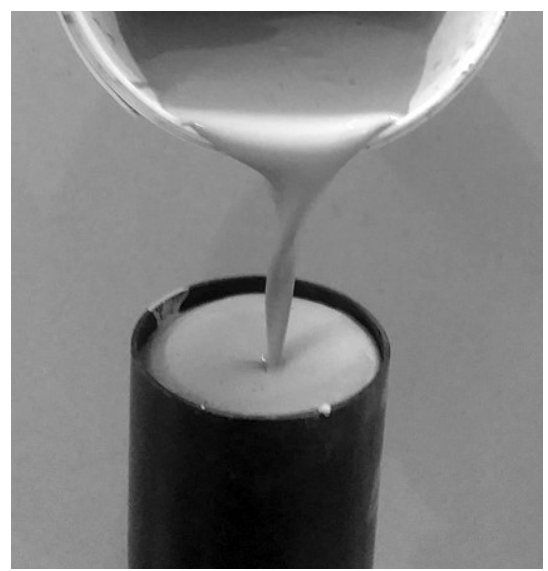

Rys. 6. Zalewanie formy negatywowej

Fig. 6. Negative form flooding czynności rozgrzaną powierzchnię powłoki negatywowej można delikatnie naciąć nożykiem z ostrzem segmentowym przez całą długość elementu, uważając równocześnie, aby nie uszkodzić odlewu.

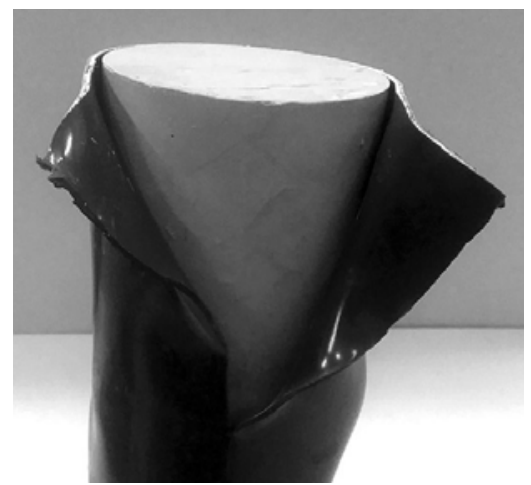

Rys. 7. Usuwanie formy negatywowej poprzez nagrzewanie opalarką i stopniowe rozrywanie formy

Fig. 7. Removing the negative form by heating with a heat gun and gradually tearing the form

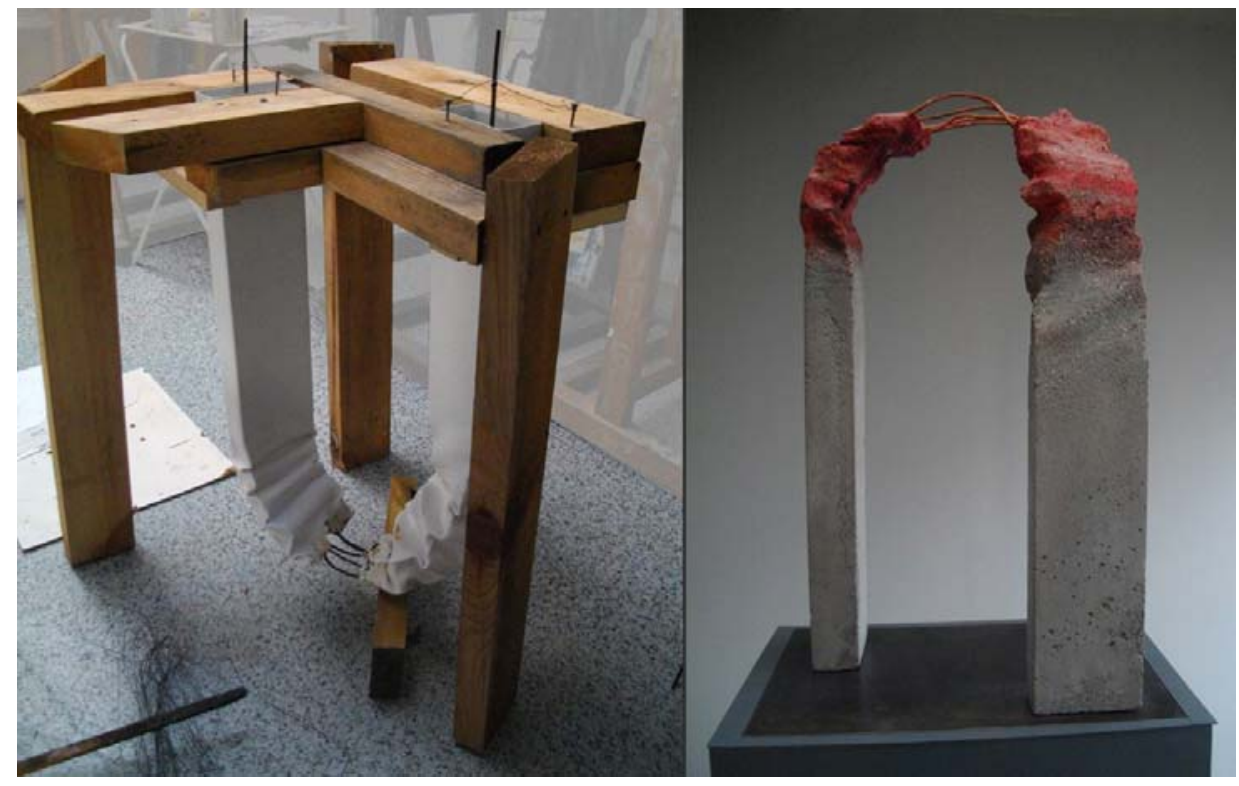

Rys. 8. Z lewej forma negatywowa uzyskana z przewodu wentylacyjnego PVC o przekroju prostokątnym, w której dokonano modyfikacji kształtu. Z prawej uzyskany odlew betonowy o formie geometrycznej, przechodzącej w płynną o organicznym charakterze. Wysokość obiektu: $61,5 \mathrm{~cm}$

Fig. 8. On the left negative form obtained from a PVC ventilation duct of rectangular cross-section, in which the shape was modified. On the right obtained concrete casting of geometric form, transforming into a fluid organic character form. Height of the object: $61.5 \mathrm{~cm}$ 
Tabela. Wyszczególnienie podstawowych cech charakteryzujących opisane w artykule metody odlewnicze na podstawie przeprowadzonych obserwacji

Table. Specification of basic features characterizing the foundry methods described in the article based on observations made

\begin{tabular}{|c|c|c|c|}
\hline $\begin{array}{l}\text { Cechy } \\
\text { Features }\end{array}$ & $\begin{array}{l}\text { Forma negatywowa gipsowa } \\
\text { Negative form plaster }\end{array}$ & $\begin{array}{c}\text { Forma negatywowa } \\
\text { z płyt (szalunek) } \\
\text { Negative form made of boards } \\
\text { (formwork) }\end{array}$ & $\begin{array}{c}\text { Negatywowa uzyskana } \\
\text { z elementu PVC } \\
\text { Negative form obtained } \\
\text { from the element PVC }\end{array}$ \\
\hline $\begin{array}{l}\text { Konieczność wykonania } \\
\text { modelu }\end{array}$ & tak & nie & nie \\
\hline Necessity of the model & yes & no & no \\
\hline $\begin{array}{l}\text { Stopień odwzorowania } \\
\text { powierzchni odlewu }\end{array}$ & bardzo dobry & bardzo dobry & bardzo dobry \\
\hline $\begin{array}{l}\text { Degree of representation } \\
\text { of the casting surface }\end{array}$ & very good & very good & very good \\
\hline $\begin{array}{l}\text { Możliwość dodatkowej } \\
\text { ingerencji w formę } \\
\text { negatywową przed } \\
\text { wykonaniem odlewu }\end{array}$ & $\begin{array}{l}\text { ograniczona } \\
\text { (rycie, szlifowanie) }\end{array}$ & nie stosuje się & $\begin{array}{l}\text { Duża, ale ograniczona } \\
\text { właściwościami } \\
\text { termoplastycznymi PVC }\end{array}$ \\
\hline $\begin{array}{l}\text { Possibility of additional } \\
\text { interference in the negative } \\
\text { form before casting }\end{array}$ & $\begin{array}{l}\text { restricted } \\
\text { (carving, grinding) }\end{array}$ & not applicable & $\begin{array}{l}\text { Large but limited } \\
\text { by thermoplastic PVC } \\
\text { properties }\end{array}$ \\
\hline
\end{tabular}

\begin{tabular}{|c|c|c|c|}
\hline $\begin{array}{l}\text { Konieczność stosowania } \\
\text { izolatora zapobiegającego } \\
\text { przywarciu materiału } \\
\text { odlewniczego (betonu) }\end{array}$ & tak & $\begin{array}{l}\text { Nie w przypadku płyt } \\
\text { wyprodukowanych } \\
\text { z PMMA lub innego } \\
\text { tworzywa sztucznego. } \\
\text { Tak w przypadku } \\
\text { meblowych płyt } \\
\text { laminowanych }\end{array}$ & nie \\
\hline $\begin{array}{l}\text { Necessity to use an insulator } \\
\text { to prevent adhesion of the } \\
\text { casting material (concrete) }\end{array}$ & yes & $\begin{array}{l}\text { Not for panels manufactured } \\
\text { from PMMA or other plastic } \\
\text { materials. Yes in the case } \\
\text { of laminated furniture boards }\end{array}$ & no \\
\hline
\end{tabular}

\begin{tabular}{lll}
\hline & $\begin{array}{l}\text { Tak, ale jedynie } \\
\text { z zachowaniem możliwości } \\
\text { dostępu i całkowitego } \\
\text { Możliwość wykonania formy } \\
\text { usunięcia materiału } \\
\text { modelunkowego bez } \\
\text { konieczności rozbierania } \\
\text { formy negatywowej } \\
\text { Yes, but only with } \\
\text { the possibility of access } \\
\text { and complete removal } \\
\text { of the modeling material } \\
\text { without the necessity } \\
\text { of disassembling the negative } \\
\text { form }\end{array}$ & \\
Possibility of making a mouk & no \\
without dividers & yes
\end{tabular}




\section{WNIOSKI}

Zastosowanie produktów z PVC jako form negatywowych do wykonania betonowych odlewów przyniosło zadowalające efekty wizualne. W wyniku przeprowadzonych prób stwierdzono, że wykonanie odlewu tego typu okazało się stosunkowo mało skomplikowanym sposobem na utrwalenie zamierzonego kształtu w betonie, zaś liczba procedur przygotowawczych była mniejsza niż w tradycyjnie praktykowanych, podstawowych metodach odlewania. Brak podziałów formy negatywowej zniwelował również konieczność późniejszego retuszowania połączeń. Dodatkową zaletą wykorzystania produktów przemysłowych jako form negatywowych była możliwość multiplikacji odlewów w przypadku realizacji obiektów składających się z kilku elementów o tej samej formie oraz wielkości. Zastosowane elementy z PVC, choć spełniły oczekiwania co do podatności na modyfikacje kształtu, równocześnie wykazały pewne ograniczenia. Zarówno w przypadku elementów o przekroju koła, jak i prostokątnym po miejscowym rozgrzaniu ścianek produktu układały się w przewidywalne formy przypominające kształtem spływającą tkaninę. Niezmienny efekt uzyskiwano przy równoczesnym zginaniu rozgrzanych fragmentów. Dodatkowa ingerencja narzędziami ręcznymi (dociskanie) nie miała istotnego wpływu na zmianę płynnego charakteru kształtu tych modyfikacji. W przypadku usuwania form negatywowych zaobserwowany stopień ingerencji i nacisku na odlew w nowej metodzie był niepomiernie mniejszy niż podczas tradycyjnego skuwana gipsowych form negatywowych.

\section{PIŚMIENNICTWO}

Guzera, J. (2010). Wykonywanie odlewów metodą wytapianych modeli w autoklawizowanych formach gipsowych. Archives of Foundry Engineering, 3 (59), 307-310.

Kaczorowski, R. (2014). Przetwórstwo tworzyw sztucznych. Techniki przetwarzania, odlewnictwo $i$ przetwórstwo tworzyw sztucznych. Łódź: Politechnika Łódzka.

Karwowski, L. (1998). Przeciw rzeźbie w przestrzeni publicznej. Orońsko - Kwartalnik Rzeźby, 4 (33), 17-22.

Pietrzak, A. i Ulewicz, M. (2019) The impact of the length of polypropylene fibers on selected properties of concrete. Acta Scientiarum Polonorum. Architectura, 18 (2), 21-25.

Piszczek, K. (2009). Żelowanie suspensyjnego, nieplastyfikowanego poli(chlorku winylu). Rozprawy 138. Bydgoszcz: Wydawnictwa Uczelniane Uniwersytetu Technologiczno-Przyrodniczego.

Šahmenko, G., Aispursb, S. i Krasnikovs, A. (2015). The Use of High Performance Cement Composite in Renovation and Restoration of Architectural Elements of Buildings Facades. Procedia Engineering, 117, 317-324.

Trillo de Leyva, J. L. i Dorado, J. A. (2018). Przeniesienia. Pretekst. Zeszyty Zakładu Architektury Mieszkaniowej i Kompozycji Architektonicznej, 8, 42-47.

Werner, J. (1978). Podstawy technologii malarstwa i grafiki. Warszawa: Wydawnictwo Naukowe PWN.

\title{
USE OF PVC FITTINGS AS NEGATIVE FORMS MOULDS FOR MAKING CONCRETE CASTINGS IN SCULPTING PRACTICE
}

\begin{abstract}
The article presents the method of casting small concrete forms with the use of products made of PVC, widely available in the trade building materials. Practical tests were carried out in order to determine the complexity of making such a casting in relation to traditional methods, of forging plaster negative forms. Tests were also carried out on the susceptibility of selected PVC construction products to shape modification before casting by local heating of the product walls with temperature of maximum $550^{\circ} \mathrm{C}$.
\end{abstract}

Key words: sculpture, casting, concrete, plaster, clay, forging 